\title{
MEDICINE AND THE LAW The research ethics evolution: From Nuremberg to Helsinki
}

\author{
A Dhai \\ Ames Dhai is Director of the Steve Biko Centre for Bioethics in the Faculty of Health Sciences, University of the Witwatersrand, \\ Johannesburg, South Africa
}

Corresponding author: A Dhai (amaboo.dhai@wits.ac.za)

\begin{abstract}
Health research sets out to acquire not only theoretical knowledge but also benefits for many people and often society as a whole, and is therefore justified. The quandary, though, is how such an important, shared purpose can be pursued with full protection of individuals and communities, in particular those with vulnerabilities. Abuses in the field surfaced in the early 1800 s, and by the 1890 s, anti-vivisectionists were calling for laws to protect children because of the increasing numbers of institutionalised children being subjected to unethical research. When read together, the Nuremberg Code and the Universal Declaration of Human Rights can be interpreted as establishing a basis for underpinning the principles of free and informed consent and avoiding harms and exploitation in scientific experiments involving human participants. The Declaration of Helsinki has been recognised as one of the most authoritative statements on ethical standards for human research in the world.
\end{abstract}

S Afr Med J 2014;104(3):178-180. DOI:10.7196/SAMJ.7864

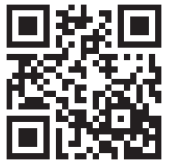

Carol Levine has stated that research ethics was 'born in scandal and reared in protectionism. ${ }^{[1]}$ Concerns about the conduct of researchers in healthcare date back to at least the end of the 19th century. ${ }^{[2]}$ Because individuals and groups were being exploited and harmed, the concept of vulnerability steadily gained prominence, ${ }^{[3-6]}$ with concerns over the participation of vulnerable individuals and groups appearing in national and international policy and guideline documents. ${ }^{[5]}$ With this surfaced the all-too-familiar tensions between scientific progress and societal interests on the one hand and individual rights and interests on the other, regarding the goals of health research. There is no question that health research sets out to acquire not only theoretical knowledge but also benefits for individuals and society as a whole, and is therefore justified. The quandary posed is how such an important, shared purpose can be pursued with full protection of individuals and communities, ${ }^{[2]}$ and those with vulnerabilities in particular.

\section{Ethical issues in health research: A historical perspective}

Even very early experiments with humans had positive outcomes. In the 1700s, James Lind, a British surgeon, studied scurvy in sailors over a 6-year period aboard the HMS Salisbury. He used an interventional study design in which some sailors were provided a diet that included fresh fruits and vegetables and others none (the control arm as in contemporary research methodologies), and in so doing was able to show that sailors in the control arm were more likely to develop scurvy than those that received fresh fruits and vegetables. ${ }^{[2,7]}$ Two and a half decades later, Edward Jenner tested the cowpox vaccine on his own and other children; the vaccinated children did not get smallpox, hence the origin of the smallpox vaccine. ${ }^{[2,8]}$

While these research successes were being celebrated, abuses were beginning to surface, and by the 1890s, anti-vivisectionists were calling for laws to protect children as a response to the increasing numbers of institutionalised children being subjected to vaccine experiments in Europe and the USA. The first attempt to test a polio vaccine was thwarted after the American Public Health Association condemned the programme. ${ }^{[6]}$ In 1897 , Giuseppe Sanarelli, an Italian bacteriologist injected five people with an organism that he had isolated to prove his postulate that it caused yellow fever. His action, which resulted in severe harm, was widely criticised ${ }^{[2]}$ and by the early 1900s, research rules were imposed by the Prussian state and the US Congress that contemplated the prohibition of medical experiments for particular groups such as pregnant women. ${ }^{[6,9]}$

In the wake of the Sanarelli scandal, Walter Reed was commissioned by the US Surgeon General to identify the cause of yellow fever, a raging epidemic in Cuba at that time. He developed ethical guidelines to act as safeguards for the research, which was to be overseen by the US Army's Yellow Fever Board. This Board could be described as the forerunner to what is today known as the Research Ethics Committee (REC) or Institutional Review Board. The guidelines included: self-experimentation by members on the Board; written contracts that clearly explained the risks involved in the experimentation for individuals who were not members of the Board (the precursor to written, informed consent forms); payment in gold for those who volunteered; US\$100 compensation for those who became ill with yellow fever; enrolment to be restricted to adults $>24$ years of age; children to be excluded; and all journal publications on the research to use the phrase 'with his full consent. ${ }^{[2,10]}$

These safeguards, utilised by the Yellow Fever Board, the contract process for obtaining explicit consent and the heroism of the Board members helped legitimise health research in the aftermath of earlier scandals. ${ }^{[2]}$ It also led to medical researchers being 'largely inoculated against regulation by the legendary status of self-experimentation by the Yellow Fever Board members. ${ }^{\text {[6] }}$ Dr Jesse Lezear died after subjecting himself to mosquito bites, confirming the hypothesis of mosquito-borne disease. ${ }^{[2,6]}$ Reed's untimely death a few years later, as a result of an error by a colleague, was mistakenly believed to be because of his involvement as a volunteer subject while on the Board. This added to the illusion that medical researchers were of such exceptionally moral character that they should be elevated to the status of martyrs ${ }^{[6]}$ Some other exemplary cases of self- 
experimentation in the 20th century include Werner Forssmann who, in 1930, practised cardiac catheterisation on himself and won a Nobel Prize in Physiology or Medicine in 1956 for his work; ${ }^{[1]]}$ and JBS Haldane who subjected himself to various gases in decompression chamber experiments in an attempt to find out how best to protect sailors in submarines. ${ }^{[11]}$ However, it was the Reed legend that served as the primary reference point and the justification for self-regulation in medical research for many decades to follow.

Notwithstanding the examples of Lind, Jenner and selfexperimentation as cited above, in the main, the first studies of experimentation on humans involved slaves and the poor. ${ }^{[1]}$ Briggle and Mitcham ${ }^{[11]}$ assert that this coincided with the development of the new science of anthropology, which Europeans used as a means to study non-European people. They state that, generally speaking, human experimentation was undertaken initially on those who were considered to be uncivilised, and often, less than human. Even colonial and imperial rule was often justified by anthropological research which described the native peoples of Africa, the Americas and Asia as being of inferior intelligence and ability and hence in need of paternalistic rule by European powers or immigrants. Their anthropological findings were based on the category of race. ${ }^{[11]}$

\section{The Nuremberg Code ${ }^{[12]}$}

Among the greatest and most notorious tragedies in human research experimentation were the heinous studies conducted during World War II by Nazi doctors on 'racially inferior' Jews and other 'deficient' groups $^{[2,3,5,6,11,13]}$ and by Japanese doctors on those people, mainly Chinese, whom they considered to be less than human. ${ }^{[1,14]}$

Lethal human experimentation - including some of the most notorious war crimes during World War II - was undertaken at Unit 731 in Northeast China, a covert biological and chemical warfare research and development unit of the Imperial Japanese Army. Up to 12000 men, women and children, 70\% of whom were Chinese, died as a result of being subjected to experimentation conducted there. Close to $30 \%$ of the subjects were Russian. Others included people from South-East Asia and the Pacific Islands. Many scientists from Unit 731 went on to acquire prominent careers after the war, in politics, academia, business and medicine. One of the probable reasons that these scientists were not tried for war crimes, akin to the trial of the Nazi scientists, is that the information and experience gained from those studies of biological warfare proved of great value for the US biological weapons development programme; it is alleged that a deal to this effect was concluded between the US and Japan in 1948. ${ }^{[14]}$

The horrors of experimentation on concentration camp inmates were publicised during the Nuremberg Trials in Germany in the aftermath of World War II. ${ }^{[2,3,5,611]}$ Nazi doctors and bureaucrats were tried by the Allies for subjecting thousands of concentration camp prisoners to egregious experiments. While 1750 victims were identified in the indictment, they represented an extremely small proportion of those killed or injured. There were 23 defendants - a token assortment selected from the 350 candidates for prosecution. ${ }^{[2,6]}$ The atrocities included anthropological studies in which hundreds of prisoners were killed so as to assemble a collection of skeletons killed because they were considered by the Nazis to be prototypes of what they called the 'repulsive but characteristic subhuman. ${ }^{[2]}$

The robust and relentless exploitation and harm prevalent in medical studies at that time cannot be overemphasised adequately. The vulnerable were considered to be subhuman, of decreased intelligence, of no moral status and as lacking human dignity. The defendants' lawyers during the Nuremberg Trial highlighted the fact that the Allies had also engaged in medical experiments in servicing the war effort, ${ }^{[6]}$ arguing that the type of medical experimentation in Nuremberg during the war was commonplace even before the war. They pointed out that there were no legal restrictions on such experiments. ${ }^{[11]}$ As the prosecution's attempts at demonstrating that there were clear international rules governing medical experimentation wavered, the judges attempted to create their own set of rules and tasked two medical advisors to the judges, Drs Andrew Ivy and Leo Alexander, with this undertaking. ${ }^{[2,6,11]}$ Drs Ivy and Alexander drafted a ten-point memorandum entitled 'Permissible Medical Experimentation, ${ }^{[11]}$ which thereafter became known as the Nuremberg Code (NC). ${ }^{[12,15]}$

Although the NC, consisting of ten characteristics for acceptable research involving humans, is among the most widely-known documents of ethics in research, ${ }^{[2]}$ and is often cited as one of the most important documents in the history of research ethics, ${ }^{[16-19]}$ it was not cited in any of the findings against the defendants and never itself became a formal part of law in Europe or North America. While it is clear that the courts believed protection was needed, it is unclear how much significance they wished to give the NC in the operations of medical research. ${ }^{[6]}$ Although they were urged by Drs Ivy and Alexander to identify persons with mental disorders as in need for special protection, the courts declined to do so. In fact, the requirement that there must always be voluntary, informed consent for all participants in any form of research undermined the relevance of the NC to research designed for vulnerable people with diminished or absent competence. ${ }^{[6]}$

Nevertheless, it would seem that the key contribution of the NC was to merge Hippocratic ethics and human rights into one code. ${ }^{[16]}$ Principles $2-8$ and 10 of the NC require that physician-researchers protect the best interests of their subjects. Principles 1 and 9 proclaim that subjects are able to protect themselves, with Principle 9 giving the subject as much authority as the physician-researcher to end participation before the conclusion of any research undertaking. ${ }^{[16]}$

Moreover, the influence of the NC on international documents is significant and the Universal Declaration of Human Rights (UDHR), ${ }^{[20]}$ adopted a year later in 1948, makes claims closely associated with the NC. ${ }^{[1]}$ The Preamble of the UDHR talks to the 'disregard and contempt of human rights that have resulted in barbarous acts which have outraged the conscience of mankind.' Article 5 states that 'No one shall be subjected to torture or to cruel, inhuman or degrading treatment or punishment.' and Article 27 states that 'Everyone has the right freely ... to share in scientific advancement and its benefits.' When read together, the NC and the UDHR can be interpreted as underpinning the principles of free and informed consent ${ }^{[11]}$ and avoiding harms and exploitation in scientific experiments involving human participants.

Despite the NC being given the status of an International Code for the ethical conduct of research at the end of the Nuremberg Trial, and despite it having substantial influence on international documents like the UDHR, for many years after the introduction of these documents, researchers continued with 'business as usual', failing to recognise that there were good reasons for protecting human research participants. ${ }^{[2,6,2]]}$ The Nazi transgressions were attributed to the abnormalities associated with a totalitarian regime with unquestionable brutality. The notion was that researchers working in democratic states would not succumb to atrocities and exploitation of vulnerable participants enrolled in research. The NC was therefore viewed as not applicable to those in civilised democracies - it was a document necessary to strain barbarians. ${ }^{[2,21]}$ However, evidence emerged in the 1950s that vulnerable individuals and populations were being exploited and harmed in research in such democracies as the US, despite the safeguards in the NC. The World Medical 
Association (WMA), perturbed by the ongoing mistreatment of research participants and also the restrictive nature of the NC regarding mandatory, informed consent from those who lacked capacity, began discussions on the ethics of research. ${ }^{[22]}$

\section{The WMA's Declaration of Helsinki}

The WMA was established in London in 1946 and held its first General Assembly in Paris in 1947. During this time, deliberations and resolutions focused on crimes committed in the doctor-patient relationship since 1933 by certain members of the medical profession in Germany during World War II. ${ }^{[2]}$ The Declaration of Geneva, ${ }^{[2]}$ an updated version of the Hippocratic Oath, and the International Code of Medical Ethics, ${ }^{[24]}$ adopted by the WMA in 1948 and 1949, respectively, were guidance documents for physicians specifically in the context of clinical care. These documents, however, have had a resounding presence in the Declaration of Helsinki as evidenced by their use in the introduction of the Declaration of Helsinki through all its revisions. Physician-researchers are bound by the words: The health of my patient will be my first consideration ${ }^{\text {?23] }}$ (Declaration of Geneva) and 'Any act or advice which could weaken physical or mental resistance of a human being may be used only in his interest ${ }^{{ }^{124 \mid}}$ (International Code of Medical Ethics). The 1964 Declaration of Helsinki was the first formal declaration by the WMA for physicians doing research and served for the first time to distinguish biomedical researchers as a specific class of physicians. ${ }^{[1]]}$ This first version was adopted after a 12 -year debate.

Since its original formulation, the Declaration of Helsinki has undergone seven revisions and two clarifications, with the most recent revision being in October $2013{ }^{[25]}$ Previously revised versions were published in 1975, 1983, 1989, 1996, 2000 and 2008. Public debate regarding the latest version has been the most intensive of any revision of the Declaration of Helsinki thus far received. Over a 2 -year period, through an open and collaborative approach, input was obtained from many expert stakeholders and organisations globally and was carefully considered during the drafting process. Four expert conferences were held and about 150 comments were reviewed. ${ }^{[25]}$ Some of the main changes include a more readable structure, revised paragraphs on vulnerable groups, RECs, post-study provisions, and the introduction of compensation for research-related injuries and a specific reference to biobanks. The Declaration of Helsinki was adopted during the WMA Assembly by an overwhelming majority $(>75 \%)$ of member associations. ${ }^{[25]}$

\section{Conclusion}

Notwithstanding criticisms of the Declaration of Helsinki, including its current revisions, by some commentators, the Declaration of Helsinki is recognised as one of the most authoritative statements on ethical standards for human research in the world. ${ }^{[26]}$ It remains the leader as it reaches its 50th anniversary this year. It is a set of principles that are regularly updated. Therefore, the Declaration of Helsinki has not lagged behind as science and technology has advanced and has kept pace with scientific progress.

1. Levine C. Has AIDS changed the ethics of human subjects research? Law Med Health Care 1998;16(34):163-173. [http://dx.doi.org/10.1111/.j.1748-720X.1988.tb01942x

2. Emanuel EJ, Crouch RA, Arras JD, Moreno JD, Grady C. Scandals and Tragedies of Research with Human Participants. In: Emanuel EJ, Crouch RA, Arras JD, Moreno JD, Grady C, eds. Ethical and Regulatory Aspects of Clinical Research. Baltimore: Johns Hopkins University Press, 2003:1-5.

3. Levine C, Faden R, Grady C, Hammerschmidt D, Eckenwiler L, Sugarman J. The limitations of 'vulnerability' as a protection for human research participants. Am J Bioeth 2004;4(3):44-49. [http:// dx.doi.org/10.1080/15265160490497083]

Macklin R. Bioethics, vulnerability and protection. Bioethics 2003;17(5-6):473-486. [http://dx.doi. org $/ 10.1111 / 1467-8519.00362$

5. Iltis AS. Introduction: Vulnerability in biomedical research. J Law Med Ethics 2009;37(1):6-11. [http:// dx.doi.org/10.1111/j.1748-720X.2009.00345.x]

6. Moreno JD. Protectionism in Research Involving Human Subjects (Research Involving Human Subjects V2). Online Ethics Centre for Engineering. 25 July 2006. http://www.onlineethics.org/Topics/ ResResearch/ResResources/nbachindex/hmoreno.aspx (accessed 20 July 2012).

ResResearch/ResResources/nbachindex/hmoreno.aspx (accessed 20 July 2012).
7. Lind J. A Treatise of the Scurvy. Edinburgh: Sands, Murray and Cochran, 1753.

7. Lind J. A Treatise of the Scurvy. Edinburgh: Sands, Murray and Cochran, 1753.

8. Jenner E. An Inquiry into the Causes and Effects of Variolae Vaccinae. London: Sampson Low, 1798. Lederer SE, Grodin MA. Historical Overview: Paediatric Experimentation. In: Grodin MA, Glantz LH, eds. Children as Research Subjects: Science, Ethics and the Law. New York: Oxford University Press, 1994. 0. Emanuel EJ, Crouch RA, Arras JD, Moreno JD, Grady C. Preface. In: Ethical and Regulatory Aspects of Clinical Research. Baltimore: Johns Hopkins University Press, 2003:xv-xviii.

11. Briggle A, Mitcham C. Research Ethics 11: Science Involving Humans. In: Briggle A, Mitcham C, eds Ethics and Science. 1st ed Cambridge: Cambridge University Press, 2012:125-155.

12. Jewish Virtual Library. The Doctors Trial: Nuremberg Code. http://www.jewishvirtuallibrary.org/ jsource/Holocaust/Nuremberg_Code.html (accessed 26 June 2013).

13. McDermott W. The changing mores of biomedical research. II. Challenge and discussion. Opening comments. Ann Intern Med 1967;67(7):39-42.

14. Unit 731. https://en.wikipedia.org/wiki/Unit_731 (accessed 27 June 2013).

15. Taylor T. Opening Statement of the Prosecution December 9, 1946. In: Annas GJ, Grodin MA, eds. The Nazi Doctors and the Nuremberg Code: Human Rights in Human Experimentation. New York: Oxford University Press, 1992:67-93.

16. Shuster E. Fifty years later: The significance of the Nuremberg Code. N Engl J Med 1997;337(20):14361440. [http://dx.doi.org/10.1056/NEJM199711133372006]

17. Moreno JD. Reassessing the influence of the Nuremberg Code on American medical ethics. J Contemp Health Law Policy 1997;13(2):347-360.

18. Katz J. The Consent Principle of the Nuremberg Code: Its Significance Then and Now. In: Annas GJ, Grodin MA, eds. The Nazi Doctors and the Nuremberg Code: Human Rights in Human Experimentation. New York: Oxford University Press, 1992:227-239.

19. Grodin MA, Annas GJ. Legacies of Nuremberg: Medical ethics and human rights. JAMA 1996;276(20):1682-1683. [http://dx.doi.org/10.1001/jama.1996.03540200068035]

20. United Nations. The Universal Declaration of Human Rights. http://www.un.org/en/documents/udhr/ (accessed 22 June 2013)

21. Faden RR, Lederer SE, Moreno JD. US medical researchers, the Nuremberg Doctors Trial, and the Nuremberg Code. A review of findings of the Advisory Committee on Human Radiation Experiments. JAMA 1996;276(20):1667-1671. [http://dx.doi.org/10.1001/jama.1996.03540200053031]

22. Human D, Fluss SS. The World Medical Association's Declaration of Helsinki: Historical and Contemporary Perspectives. Ferney-Voltaire: WMA, 2001. http://www.wma.net/en/20activities/10eth ics/10helsinki/draft_historical_contemporary_perspectives.pdf (accessed 29 June 2013).

23. World Medical Association. WMA Declaration of Geneva. http://www.wma.net/ World Medical Association. WMA Declaration of G
en/30publications/10policies/g1/index.html (accessed 29 June 2013).

24. World Medical Association. WMA International Code of Medical Ethics. http://www.wma.net/ en/30publications/10policies/c8/index.html (accessed 29 June 2013).

25. World Medical Association. World Medical Journal 2013;59(5). http://www.wma.net/ en/30publications/20journal/pdf/wmj201305.pdf (accessed 17 December 2013).

26. Kimmelman J, Weijer C, Meslin EM. The Helsinki Discords: FDA, ethics and international drug trials. Lancet 2009;373(9657):13-14. [http://dx.doi.org/10.1016/S0140-6736(08)61936-4]

Accepted 6 January 2014. 